\title{
Clinical Behavior of Bladder Urothelial Carcinoma in Young Patients: A Single Center Experience
}

\author{
Volkan Sen, Ozan Bozkurt, Omer Demir, Ahmet Adil Esen, Ugur Mungan, \\ Guven Aslan, Aykut Kefi, and Ilhan Celebi \\ Department of Urology, Dokuz Eylul University School of Medicine, 35330 Izmir, Turkey \\ Correspondence should be addressed to Volkan Sen; sen_volkan@yahoo.com
}

Received 20 December 2015; Revised 1 June 2016; Accepted 3 July 2016

Academic Editor: Stanley Bruce Malkowicz

Copyright (c) 2016 Volkan Sen et al. This is an open access article distributed under the Creative Commons Attribution License, which permits unrestricted use, distribution, and reproduction in any medium, provided the original work is properly cited.

\begin{abstract}
Background. There is not enough evidence about clinical behavior of bladder cancer in younger patients. Objective. We aimed to evaluate the clinical characteristics and prognosis of bladder urothelial carcinoma patients under the age of 40 years. Methods. Medical records of patients listed in our cancer database were retrospectively reviewed. A total of 40 patients who were initially diagnosed with bladder urothelial carcinoma at the age less than 40 years were included in the study. Patients' records were reviewed for recurrence and progression rates, demographic data, medical history, and treatment modalities. Results. Pathological results revealed $33(82.5 \%)$ Ta low-grade, 6 (15\%) T1 high-grade, and $1(2.5 \%)$ T2 high-grade urothelial carcinomas. Recurrence was detected in $14 / 39$ (35.9\%) patients but progression was not observed in any patients. The mean age of recurrent patients was significantly higher than nonrecurrent patients ( 34.8 versus 28.5 years; $p<0.05$ ). Besides, recurrence was detected in only 1 patient with the age under 30 years $(6.2 \%)$ and 13 patients $(54.1 \%)$ between 30 and 40 years old, respectively $(p<0.05)$. Conclusion. Bladder urothelial carcinoma diagnosed at young age tends to be a low pathologic stage, with relatively low rate of recurrence and progression.
\end{abstract}

\section{Introduction}

Bladder cancer $(\mathrm{BC})$ is the most common malignancy of the urinary tract [1]. More than $90 \%$ of bladder cancer is urothelial carcinoma and $70-80 \%$ of patients have nonmuscle-invasive tumors at presentation [2]. Bladder urothelial carcinomas are more frequent in elderly patients with the median ages of initial diagnosis being 69 and 71 years in men and women, respectively $[3,4]$. The clinical behavior of bladder urothelial carcinoma is a variable; the risk factors such as pathological stage and grade, presence of concurrent CIS, and tumor size and number constitute this variety. Although the risk factors and treatment modalities of bladder cancer have been well studied, conflicting reports exist about clinical behavior and prognosis for younger patients. This situation may be related to the rarity of bladder cancer in patients younger than 40 years old [5-8]. Some studies have reported that younger patients with bladder urothelial carcinomas had similar prognosis with older patients [9], but some of the studies showed that younger patients had better prognosis $[10,11]$. We aimed to evaluate the clinical behavior and prognosis of bladder urothelial carcinoma patients under the age of 40 years.

\section{Materials and Methods}

Medical records of patients listed in our cancer database with diagnosis of bladder urothelial carcinoma between the years of 1990-2009 were retrospectively reviewed. A total of 40 patients who were initially diagnosed with bladder urothelial carcinoma at the age less than 40 years were included in the study. Data were recorded regarding their presenting symptoms, family history, and any exposure to occupational risk factors. Patients' records were also reviewed for recurrence and progression rates, demographic data, medical history, and treatment modalities. Tumors were staged according to the TNM staging system and graded according to the grading scheme proposed by World Health Organization (WHO) $[12,13]$.

Follow-up consisted of white light cystoscopy every 3 months for the first 2 years, every 6 months between second 
TABLE 1: Age distribution of patients.

\begin{tabular}{lc}
\hline Age range (years) & $N(\%)$ \\
\hline $10-20$ & $3(7.5 \%)$ \\
$20-30$ & $13(32.5 \%)$ \\
$30-40$ & $24(60 \%)$ \\
\hline
\end{tabular}

TABLE 2: Clinical and pathological results of patients for different age groups.

\begin{tabular}{lcc}
\hline & $<30$ years old & $30-40$ years old \\
\hline Ta urothelial carcinoma & $15(93.8 \%)$ & $18(75 \%)$ \\
T1 urothelial carcinoma & $1(6.2 \%)$ & $5(20.8 \%)$ \\
T2 urothelial carcinoma & - & $1(4.2 \%)$ \\
Smoking & $11(68.7 \%)$ & $14(58.3 \%)$ \\
Recurrence rate & $1 / 16(6.2 \%)$ & $13 / 24(54.1 \%)$ \\
Progression rate & - & $\mathbf{p}<\mathbf{0 . 0 5}$ \\
\hline
\end{tabular}

and fifth years, and then annually. Recurrence was considered as histological evidence of malignancies of the same or lower stage and grade. Tumor progression was defined as histologically confirmed muscle-invasive bladder cancer or evidence of metastatic disease.

2.1. Statistical Analysis. The statistical software package SPSS 20.0 version (SPSS Inc., Chicago, IL, USA) was employed for data management and analysis. Data were summarized with percentage, distribution, mean, standard deviation, and median values. Chi-square test was performed. Significance was set at $p \leq 0.05$.

\section{Results}

A total of 40 patients were evaluated and median follow-up time was 54 (8-167) months. There were 7 (17.5\%) women and $33(82.5 \%)$ men. The mean age was $30.9(10-39)$ years. The age distribution of patients was given in Table 1 . The most common risk factor was smoking (25 patients; 62\%). 33 (82.5\%) patients had single tumor and $7(17.5 \%)$ patients had tumors bigger than $3 \mathrm{~cm}$. Pathological results revealed $33(82.5 \%) \mathrm{Ta}$ low-grade, 6 (15\%) T1 high-grade, and 1 (2.5\%) T2 high-grade urothelial carcinomas. Radical cystectomy was performed on only one patient. 16 patients were under the age of 30 and 24 patients were between 30 and 40 years old. Recurrence was detected in 14/39 (35.9\%) patients but progression was not observed in any patients. Nine recurrent patients had primary Ta low-grade urothelial carcinoma and 5 recurrent patients had primary T1 high-grade urothelial carcinoma. The mean age of recurrent patients was significantly higher than nonrecurrent patients (34.8 versus 28.5 years; $p<0.05$ ). Besides, recurrence was detected in only 1 patient with the age under 30 years $(6.2 \%)$ and 13 patients $(54.1 \%)$ between 30 and 40 years old, respectively $(p<0.05)$. The other possible predictive parameters for recurrence were similar between groups (Table 2).

\section{Discussion}

Bladder urothelial carcinoma is the most common malignancy of urinary tract; however, it is a very rare condition in young patients with the rate of $0.4 \%$ to $2.0 \%$ [5-8]. Because of its rarity there is a debate in the literature about the clinical behavior of bladder urothelial carcinoma in younger patients. Hematuria, the most common presenting symptom in bladder urothelial carcinomas in young patients [14], was detected in $85 \%$ patients $(34 / 40)$ in our study. There was no significant difference between the recurrent and nonrecurrent patients regarding the occurrence of gross hematuria. Male/female ratio in our study was 4.7/1, similar to the literature [15]. Tobacco smoking is the most important risk factor for bladder urothelial carcinoma, accounting for approximately $50 \%$ of cases in the literature and $62 \%$ in our series $[16,17]$. Bladder urothelial carcinomas in younger patients usually have a lower grade and stage than older patients $[10,18$, 19]. With the increasing of age, the incidence of low-grade urothelial carcinoma decreases and high-grade urothelial tumor rate increases [20]. Our findings supported that the patients under 40 years old usually present with low stage and low-grade bladder cancer. Also younger patients have less recurrence and progression rates than older ones. Nonmuscle-invasive bladder urothelial carcinoma was detected in $97.5 \%$ of our patients and only 1 patient had invasive tumor. Recurrence was detected in 14 (35\%) patients but progression was not observed in any patients in our study. The comparison of patients aged $<30$ and 30-40 years revealed that recurrence was significantly higher in 30-40-year-old group. Our results and several published reports showed that tumor recurrence does seem to be age-related [21].

Although several tumor markers such as p53, pRb, HYAL1 , and nestin were evaluated for the prognosis of non-muscleinvasive bladder urothelial carcinomas, they could not take a place in routine clinical use [22-24]. Even if microsatellite instability and p53 were found to be associated with clinical behavior and prognosis of younger patients, further comprehensive studies including larger patient cohorts are needed to clarify this relationship [20,25].

The prognosis of invasive bladder urothelial carcinoma in younger patients tends to be very poor. Yossepowitch and Dalbagni reported that the 5-year rate of disease-free survival after cystectomy was only $59 \%$ in 17 patients [19]. We performed cystectomy only in 1 patient for invasive bladder urothelial carcinoma and his survival was 24 months.

The main limitation of present study was its retrospective design. The staging, grading, and treatment modalities of bladder urothelial carcinoma had changed over years so the clinical outcomes might be affected by these changes in this period.

\section{Conclusions}

Bladder urothelial carcinoma diagnosed at young age tends to be a low pathologic stage, with relatively low rate of recurrence and progression. Therefore, more conservative management approaches in a long follow-up are needed for young patients with bladder cancer. 


\section{Competing Interests}

The authors have no competing interests.

\section{References}

[1] M. Babjuk, M. Burger, R. Zigeuner et al., "EAU guidelines on non-muscle-invasive urothelial carcinoma of the bladder: update 2013," European Urology, vol. 64, no. 4, pp. 639-653, 2013.

[2] J. A. Witjes and K. Hendricksen, "Intravesical pharmacotherapy for non-muscle-invasive bladder cancer: a critical analysis of currently available drugs, treatment schedules, and long-term results," European Urology, vol. 53, no. 1, pp. 45-52, 2008.

[3] M. J. Hayat, N. Howlader, M. E. Reichman, and B. K. Edwards, "Cancer statistics, trends, and multiple primary cancer analyses from the Surveillance, Epidemiology, and End Results (SEER) Program," Oncologist, vol. 12, no. 1, pp. 20-37, 2007.

[4] C. F. Lynch and M. B. Cohen, "Urinary system," Cancer, vol. 75, no. 1, pp. 316-329, 1995.

[5] B. Gunlusoy, Y. Ceylan, T. Degirmenci et al., "Urothelial bladder cancer in young adults: diagnosis, treatment and clinical behaviour," Canadian Urological Association Journal, vol. 9, no. 9-10, pp. E727-E730, 2015.

[6] H. Huang, M. Sun, X. Li, and J. Jin, "Urothelial carcinoma of the bladder in patients aged 30 years or younger: clinicopathological analysis and expression of fibroblast growth factor receptor 3 (FGFR3) of 45 cases," Medical Oncology, vol. 32, no. 5, article 137, 2015.

[7] Q.-H. Wang, Z.-G. Ji, H.-Z. Li et al., "Clinicopathologic comparison of urothelial bladder carcinoma in young and elder patients," Pathology and Oncology Research, vol. 22, no. 1, pp. 67-70, 2016.

[8] Y.-C. Wen, J.-Y. Kuo, K.-K. Chen et al., "Urothelial carcinoma of the urinary bladder in young adults-clinical experience at Taipei Veterans General Hospital," Journal of the Chinese Medical Association, vol. 68, no. 6, pp. 272-275, 2005.

[9] M. Nomikos, A. Pappas, M.-E. Kopaka et al., "Urothelial carcinoma of the urinary bladder in young adults: presentation, clinical behavior and outcome," Advances in Urology, vol. 2011, Article ID 480738, 4 pages, 2011.

[10] E. Compérat, S. Larré, M. Roupret et al., "Clinicopathological characteristics of urothelial bladder cancer in patients less than 40 years old," Virchows Archiv, vol. 466, no. 5, pp. 589-594, 2015.

[11] S. Poletajew, M. Walędziak, Ł. Fus, P. Pomada, J. Ciechańska, and A. Wasiutyński, "Urothelial bladder carcinoma in young patients is characterized by a relatively good prognosis," Upsala Journal of Medical Sciences, vol. 117, no. 1, pp. 47-51, 2012.

[12] L. Cheng, R. Montironi, D. D. Davidson, and A. Lopez-Beltran, "Staging and reporting of urothelial carcinoma of the urinary bladder," Modern Pathology, vol. 22, supplement 2, pp. S70-S95, 2009.

[13] J. I. Epstein, M. B. Amin, V. R. Reuter et al., "The World Health Organization/International Society of Urological Pathology consensus classification of urothelial (transitional cell) neoplasms of the urinary bladder," The American Journal of Surgical Pathology, vol. 22, no. 12, pp. 1435-1448, 1998.

[14] S. B. A. Lee, H. S. U. Kim, M. Kim, and J. H. Y. Ku, "External validation of a clinical scoring system for hematuria," Asian Pacific Journal of Cancer Prevention, vol. 15, no. 16, pp. 68196822, 2014.
[15] Z.-H. Wang, Y.-Y. Li, Z.-Q. Hu et al., "Does urothelial cancer of bladder behave differently in young patients?" Chinese Medical Journal, vol. 125, no. 15, pp. 2643-2648, 2012.

[16] A. Otunctemur, I. Koklu, E. Ozbek et al., "Are bladder neoplasms more aggresive in patients with a smoking-related second malignancy?" Asian Pacific Journal of Cancer Prevention, vol. 15, no. 9, pp. 4025-4028, 2014.

[17] N. D. Freedman, D. T. Silverman, A. R. Hollenbeck, A. Schatzkin, and C. C. Abnet, "Association between smoking and risk of bladder cancer among men and women," JAMA, vol. 306, no. 7, pp. 737-745, 2011.

[18] M. Migaldi, G. Rossi, A. Maiorana et al., "Superficial papillary urothelial carcinomas in young and elderly patients: a comparative study," BJU International, vol. 94, no. 3, pp. 311-316, 2004.

[19] O. Yossepowitch and G. Dalbagni, "Transitional cell carcinoma of the bladder in young adults: presentation, natural history and outcome," Journal of Urology, vol. 168, no. 1, pp. 61-66, 2002.

[20] G. P. Paner, P. Zehnder, A. M. Amin, A. N. Husain, and M. M. Desai, "Urothelial neoplasms of the urinary bladder occurring in young adult and pediatric patients: a comprehensive review of literature with implications for patient management," Advances in Anatomic Pathology, vol. 18, no. 1, pp. 79-89, 2011.

[21] R. C. Benson Jr., K. M. Tomera, and P. P. Kelalis, "Transitional cell carcinoma of the bladder in children and adolescents," Journal of Urology, vol. 130, no. 1, pp. 54-55, 1983.

[22] V. Sen, O. Bozkurt, O. Demir et al., "Prognostic significance of nestin expression in pT1 high-grade bladder urothelial carcinoma patients treated with intravesical BCG," Asian Pacific Journal of Cancer Prevention, vol. 15, no. 24, pp. 10813-10817, 2014.

[23] L. Lima, M. Dinis-Ribeiro, A. Longatto-Filho, and L. Santos, "Predictive biomarkers of bacillus Calmette-Guérin immunotherapy response in bladder cancer: where are we now?" Advances in Urology, vol. 2012, Article ID 232609, 17 pages, 2012.

[24] E. Mammadov, G. Aslan, B. Tuna, O. Bozkurt, and K. Yorukoglu, "Can recurrence and progression be predicted by HYAL-1 expression in primary T1 bladder cancer?” Asian Pacific Journal of Cancer Prevention, vol. 15, no. 23, pp. 10401-10405, 2014.

[25] M. Christensen, M. A. Jensen, H. Wolf, and T. F. Ørntoft, "Pronounced microsatellite instability in transitional cell carcinomas from young patients with bladder cancer," International Journal of Cancer, vol. 79, no. 4, pp. 396-401, 1998. 


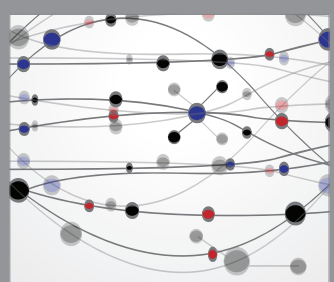

The Scientific World Journal
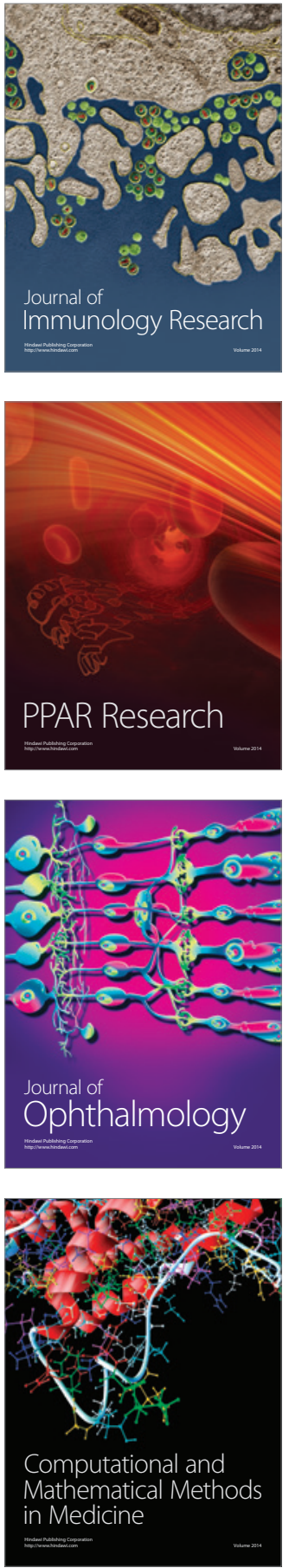

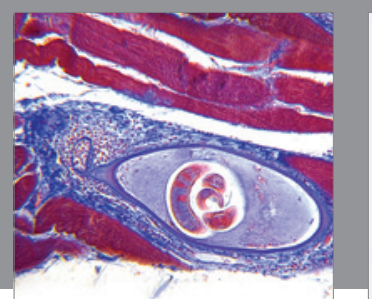

Gastroenterology Research and Practice

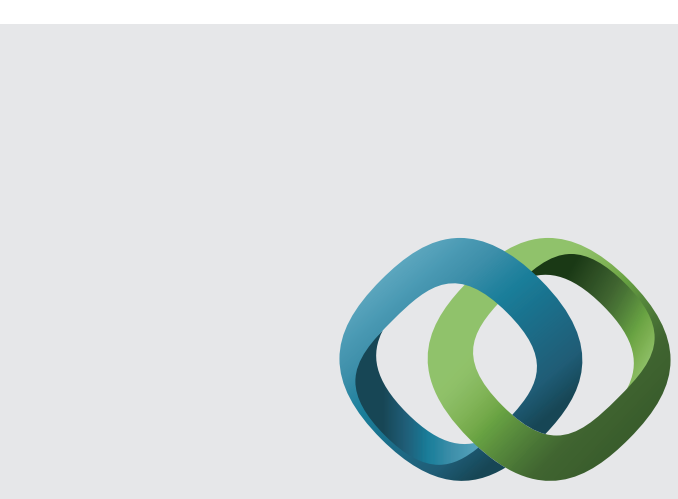

\section{Hindawi}

Submit your manuscripts at

http://www.hindawi.com
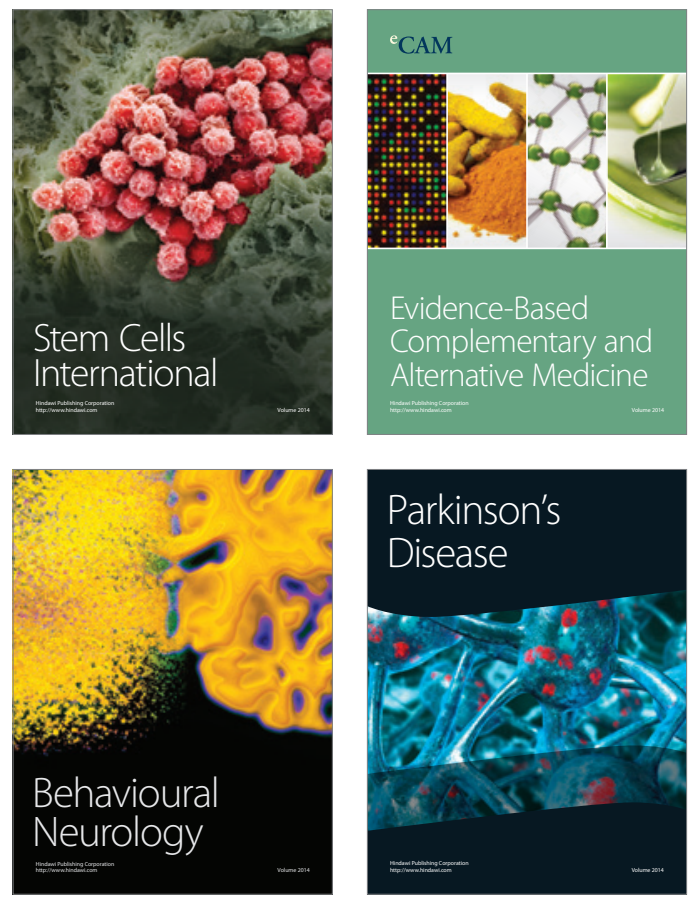
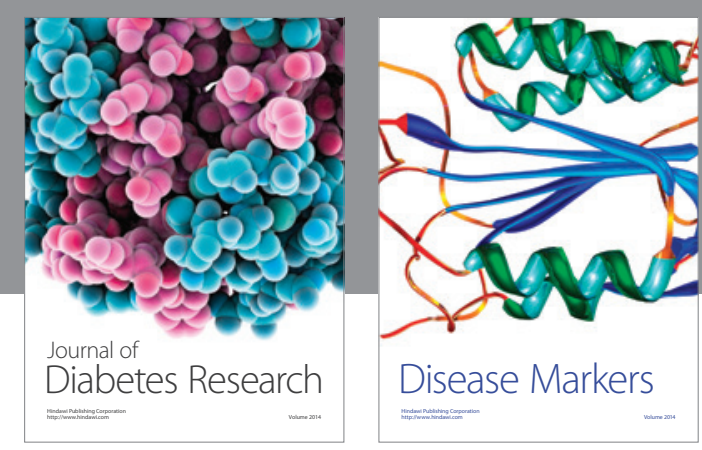

Disease Markers
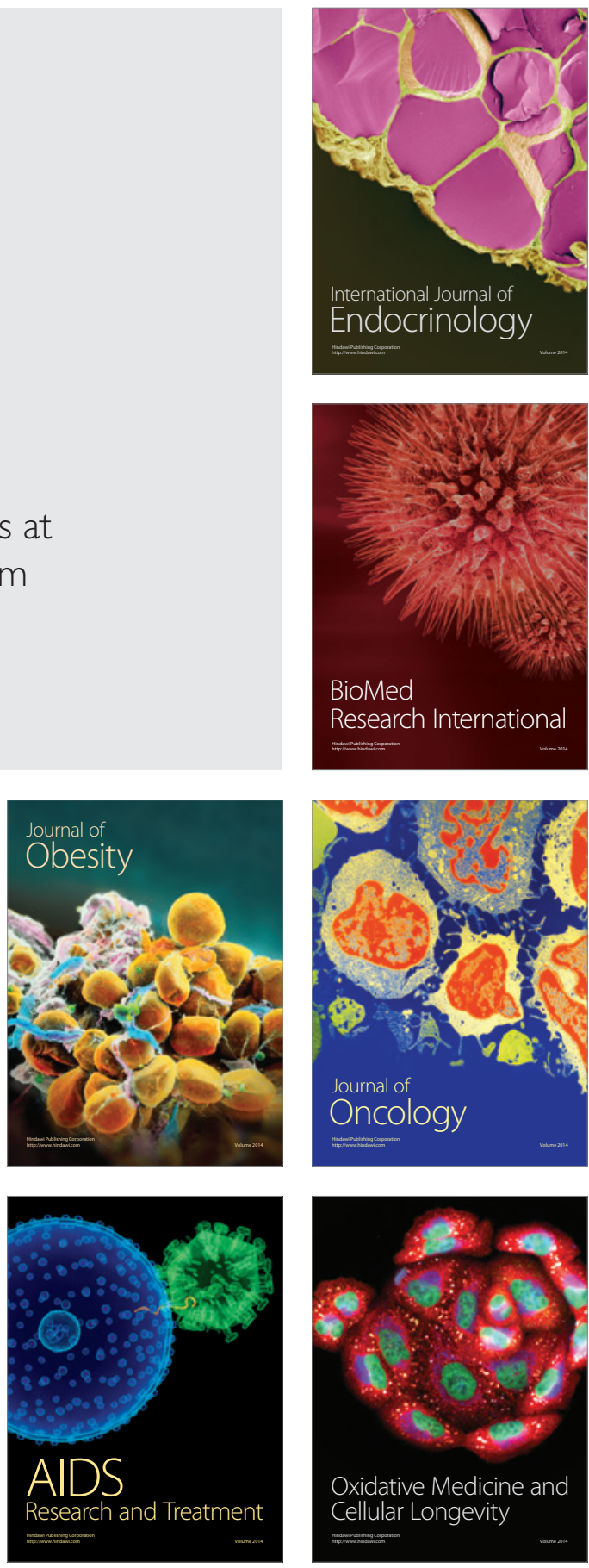